\title{
Influence Of Time Under Mechanical Ventilation On Bronchopulmonary Dysplasia Severity In Extremely Preterm Infants: A Pilot Study.
}

\section{CURRENT STATUS: UNDER REVISION}

BMC Pediatrics $\triangle \mathbf{B M C}$ series

Vanessa Suziane Probst

Universidade Estadual de Londrina Centro de Ciencias da Saude

ح vanessaprobst@gmail.comCorresponding Author

ORCiD: https://orcid.org/0000-0003-1483-5319

\section{Victoria Escobar}

Universidade Estadual da Londrina Hospital Universitario da UEL

\section{Darllyana Soares}

Universidade Estadual da Londrina Hospital Universitario da UEL

\section{Jane Kreling}

Universidade Estadual da Londrina Hospital Universitario da UEL

\section{Ligia Ferrari}

Universidade Estadual da Londrina Hospital Universitario da UEL

Josiane M. Felcar

Universidade Estadual de Londrina

Carlos A. M. Camillo

Universidade Estadual de Londrina

\section{DOI:}

$10.21203 / \mathrm{rs} .2 .23724 / \mathrm{v} 1$

\section{SUBJECT AREAS}

Pediatrics

\section{KEYWORDS}

Premature, Bronchopulmonary Dysplasia, Mechanical Ventilation 
Abstract

The relation between mechanical ventilation (MV) and bronchopulmonary dysplasia (BPD) is well stabilished, but is unknown, however, how much time under MV influences the severity of the disease. Aim: To define the duration under MV with greater chance to develop moderate to severe BPD (M/S BPD) in extremely PTNB and to compare clinical outcomes before and during hospitalization among patients with mild and M/S BPD.

Methods: 53 PTNB were separated into mild and M/S BPD groups and their data were analyzed. Time under MV with a greater chance of developing M/S BPD was estimated by the ROC curve. Perinatal and hospitalization outcomes were compared between groups. A logistic regression was performed to verify the influence of variables associated to M/S BPD development, such as pulmonary hypertension $(\mathrm{PH})$, gender, gestational age (GA) and weight at birth, as well the time under MV found with ROC curve. The result of ROC curve was validated using an independent sample $(n=16)$ by Chi-square test. Results: Time under MV related to a greater chance of developing M/S BPD was 36 days. M/S BPD group had more males (14 vs 5, $p=0,047$ ), longer time under MV (43 vs 19 days, $p<0,001)$, more individuals with PH (12 vs $3, p=0,016$ ), worse retinopathy of prematurity (grade 3,2 vs $11, p=0,003$ ), longer hospital length of stay (109 vs 81,5 days, $p<0,001$ ), greater PMA (41 vs 38 weeks, $p<0,001$ ) and weight (2620 vs 2031 grams, p<0,001) at discharge and the mild BPD group had more CPAP use prior to MV (12 vs 7, $\mathrm{p}=0,043$ ). Among all variables included in logistic regression, only $\mathrm{PH}$ and $M V<36$ days were significant in the model, explaining $72 \%$ of variation in M/S BPD development. In the validation sample, prevalence of preterm infants who needed MV for more than 36 days in the M/S BPD group was $100 \%(n=6)$ and $0 \%$ in mild BPD group $(p=0,0001)$.

Conclusion: Time under MV related to moderate to severe BPD development is 36 days, and worst outcomes are related to disease severity. $\mathrm{PH}$ and time under MV for more than 36 days are related to development of M/S BPD.

Full Text

Due to technical limitations, full-text HTML conversion of this manuscript could not be completed. However, the manuscript can be downloaded and accessed as a PDF.

Figures 


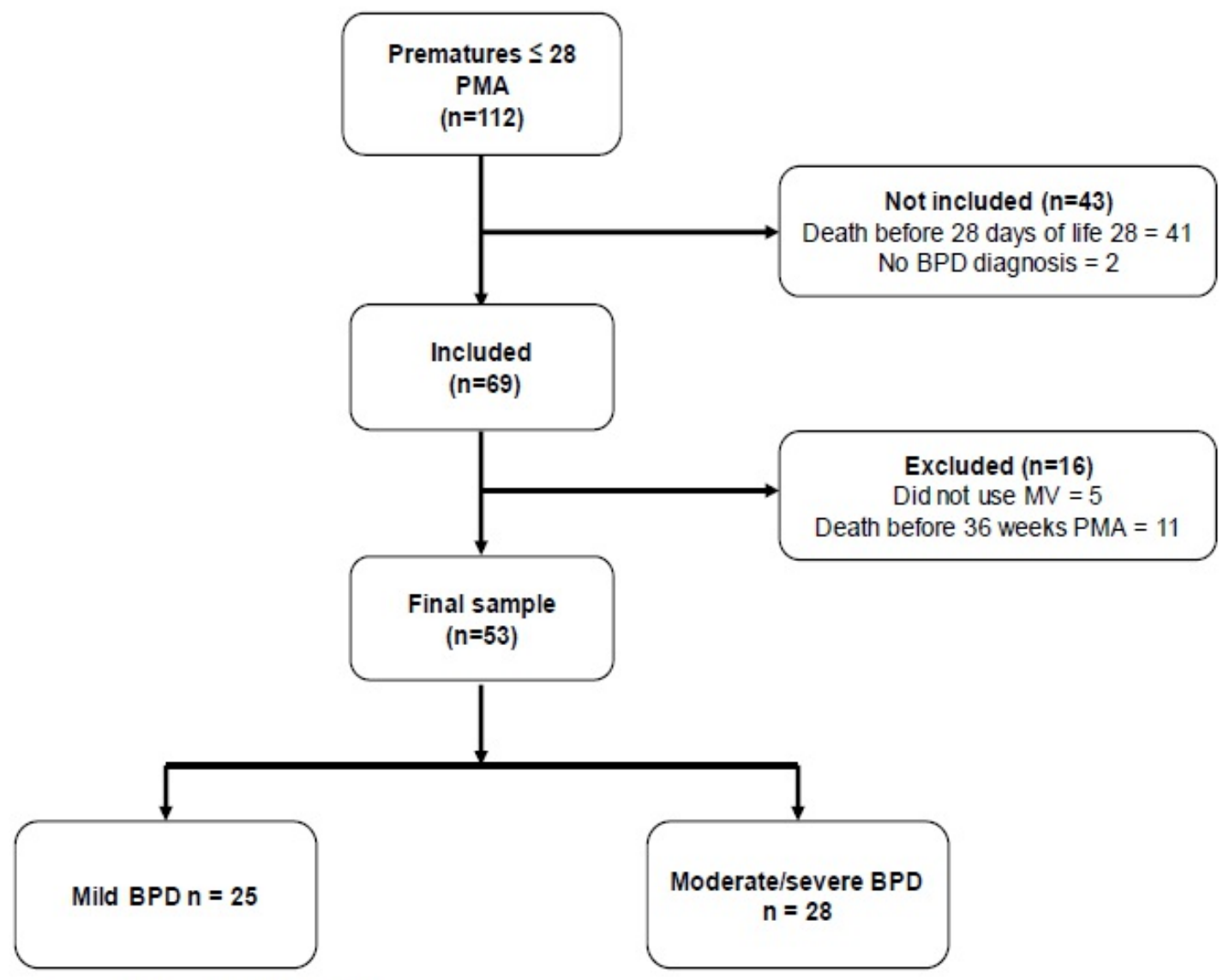

Figure 1. Flowchart of the study.

Figure 1

Flowchart of the study. 


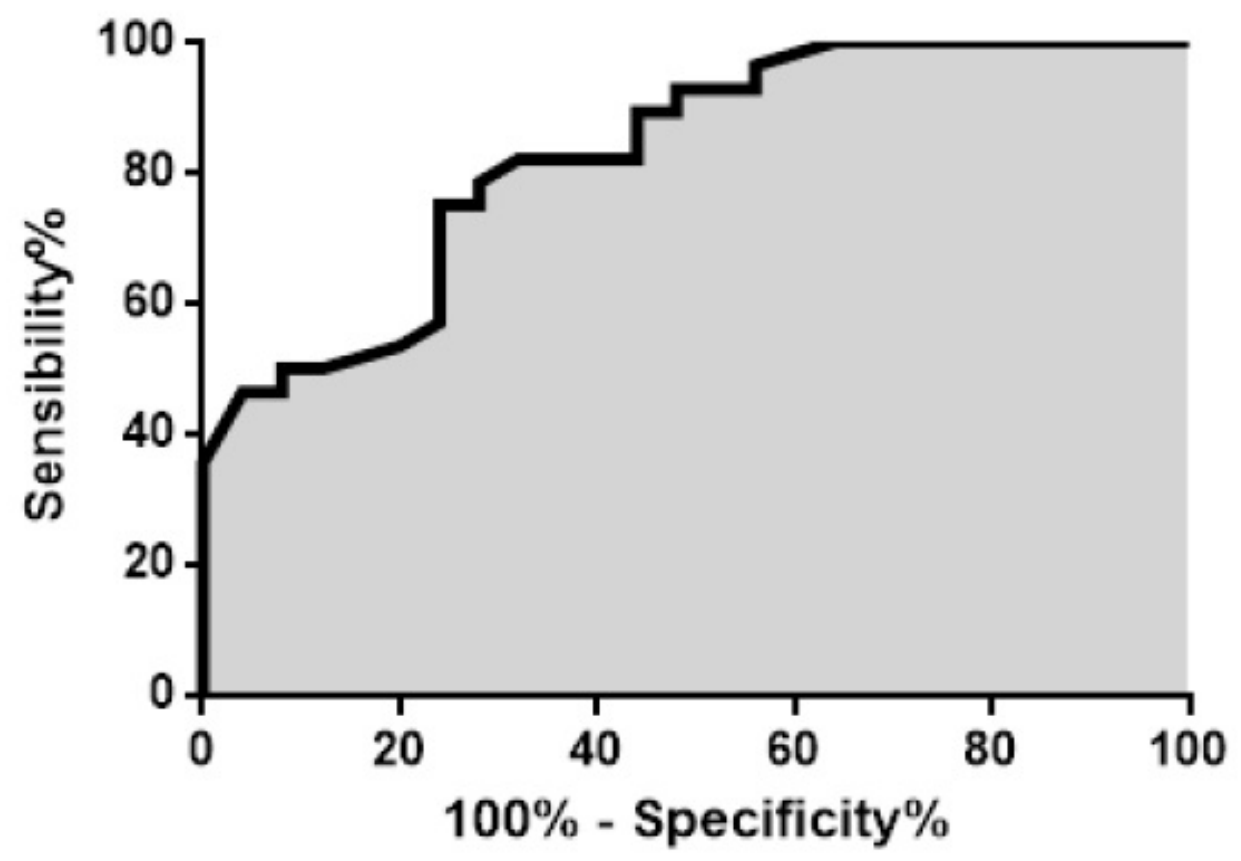

Figure 2

Cut-off point of time under mechanical ventilation. ROC curve showing sensibility and specificity of time under MV with greater chance to develop moderate/severe BPD. Area under the curve 0,83 .

\section{Supplementary Files}

This is a list of supplementary files associated with this preprint. Click to download.

STROBE_Escobar et al.docx 